\title{
Resveratrol inhibits BMP-4-stimulated VEGF synthesis in osteoblasts: Suppression of S6 kinase
}

\author{
AKIRA KONDO $^{1,2}$, TAKANOBU OTSUKA ${ }^{1}$, GEN KUROYANAGI ${ }^{1,2}$, NAOHIRO YAMAMOTO $^{1,2}$, \\ RIE MATSUSHIMA-NISHIWAKI ${ }^{2}$, JUN MIZUTANI ${ }^{1}$, OSAMU KOZAWA $^{2}$ and HARUHIKO TOKUDA ${ }^{2,3}$ \\ ${ }^{1}$ Department of Orthopedic Surgery, Nagoya City University Graduate School of Medical Sciences, Nagoya, Aichi 467-8601; \\ ${ }^{2}$ Department of Pharmacology, Gifu University Graduate School of Medicine, Gifu, Gifu 501-1194; \\ ${ }^{3}$ Department of Clinical Laboratory, National Center for Geriatrics and Gerontology, Obu, Aichi 474-8511, Japan
}

Received October 7, 2013; Accepted December 23, 2013

DOI: $10.3892 /$ ijmm.2014.1626

\begin{abstract}
Resveratrol is well known as a natural polyphenol abundantly found in red wine. We previously reported that bone morphogenetic protein-4 (BMP-4) stimulates vascular endothelial growth factor (VEGF) synthesis via p70 S6 kinase in osteoblast-like MC3T3-E1 cells. In the present study, we investigated the effect of resveratrol on the BMP-4-stimulated VEGF synthesis in MC3T3-E1 cells. Resveratrol significantly suppressed BMP-4-stimulated release and expression levels of VEGF mRNA. SRT1720, an activator of SIRT1 with potencies greater than resveratrol, also reduced VEGF release and the mRNA levels. Both resveratrol and SRT1720 markedly attenuated the BMP-4-induced phosphorylation of p70 S6 kinase without affecting the BMP-4-induced phosphorylation of Smad1/5/8. These findings strongly suggest that resveratrol attenuates BMP-4-stimulated VEGF synthesis through suppression of the activation of p70 S6 kinase in osteoblasts, and that the inhibitory effect is mediated at least in part by SIRT1 activation.
\end{abstract}

\section{Introduction}

Bone metabolism is strictly regulated by osteoblasts and osteoclasts, which are responsible for bone formation and bone resorption, respectively (1). These functional cells are considered to affect one another via humoral factors as well as by direct cell-to-cell interaction. It has been firmly established that osteoblasts also play a crucial role in the regulation of bone resorption through receptor activator of nuclear factor- $\kappa \mathrm{B}$ ligand (RANKL) expression in response to a variety of bone resorptive stimuli (2). The resorption of preexisting bone by

Correspondence to: Dr Haruhiko Tokuda, Department of Clinical Laboratory, National Center for Geriatrics and Gerontology, Obu, Aichi 474-8511, Japan

E-mail: tokuda@ncgg.go.jp

Key words: resveratrol, bone morphogenetic protein-4, vascular endothelial growth factor, osteoblast osteoclasts and the formation of new bone by osteoblasts, bone remodeling, is a strictly coordinated process to maintain adequate bone mass. The disorder of bone remodeling causes metabolic bone diseases such as osteoporosis and fracture healing distress. In the process of bone remodeling, it is generally recognized that numerous humoral factors including cytokines and growth factors play pivotal roles (3).

Bone morphogenetic proteins (BMPs) are multifunctional cytokines and belong to the transforming growth factor- $\beta$ (TGF- $\beta$ ) superfamily (4). It is well known that BMPs expressed in bone are essential for skeletal development and bone remodeling (5). The effects of BMPs on osteoblasts are exerted through Smad (Smad1/5/8)-dependent signaling and Smadindependent signaling such as the mitogen-activated protein (MAP) kinase family $(4,6)$. Moreover, vascular endothelial growth factor (VEGF) is currently recognized to play critical roles in effective coupling of angiogenesis and osteogenesis (7). Among bone cells, the osteoblast lineage is considered as a major source of VEGF (7). In addition, the receptors for VEGF are expressed both on osteoblasts and osteoclasts (7). The production of VEGF by osteoblasts is reportedly modulated by a wide range of stimulations including hormonal, mechanical and environmental influences, suggesting that VEGF synthesis by osteoblasts plays a crucial role for the control of angiogenesis in bone via an autocrine and/or paracrine mechanism (7). We previously demonstrated that BMP-4 stimulates VEGF synthesis through activation of p70 S6 kinase in osteoblast-like MC3T3-E1 cells $(8,9)$.

It has been firmly established that polyphenolic compounds in foods such as vegetables and fruits confer beneficial effects on human being. It has been reported that flavonoids, among the polyphenolic compounds, possess antioxidative, anti-inflammatory and anti-tumor effects $(10,11)$. Resveratrol, a natural polyphenol found abundantly in the skins of red grapes and red wine, has recently received increased attention as a means to improve health and prolong life $(12,13)$. In mammalian cells, the effects of resveratrol are recognized to be dependent upon SIRT1, known as a longevity gene, improving the function of cells and organs via activation of the nicotinamide adenine dinucleotide $\left(\mathrm{NAD}^{+}\right)$-dependent deacetylase (14). Regarding the effects of resveratrol on bone, it has been shown that resveratrol promotes osteoblast differentiation $(15,16)$. However, 
the exact mechanisms underlying the effects of resveratrol on bone metabolism have not yet been clarified.

In the present study, we investigated the effect of resveratrol on BMP-4-stimulated VEGF synthesis in osteoblast-like MC3T3-E1 cells and the related mechanisms. We demonstrated that resveratrol suppresses BMP-4-stimulated VEGF synthesis via inhibition of p70 S6 kinase in these cells.

\section{Materials and methods}

Materials. Resveratrol and SRT1720 were obtained from Calbiochem-Novabiochem Co. (La Jolla, CA, USA). BMP-4 and mouse VEGF enzyme-linked immunosorbent assay (ELISA) kits were obtained from R\&D Systems, Inc. (Minneapolis, MN, USA). Phospho-specific Smad1/5/8 antibodies, phospho-specific p70 S6 kinase antibodies and p70 S6 kinase antibodies were obtained from Cell Signaling Technology, Inc. (Beverly, MA, USA). Glyceraldehyde-3phosphate dehydrogenase (GAPDH) antibodies were obtained from Santa Cruz Biotechnology, Inc. (Santa Cruz, CA, USA). An ECL Western blotting detection system was obtained from GE Healthcare (Buckinghamshire, UK). TRIzol reagent was purchased from Invitrogen, Co. (Carlsbad, CA, USA). FastStart DNA Master SYBR-Green I was purchased from Roche Diagnostics (Mannheim, Germany). Omniscript Reverse Transcriptase kit was purchased from Qiagen, Inc. (Hilden, Germany). Other materials and chemicals were obtained from commercial sources. Resveratrol and SRT1720 were dissolved in dimethyl sulfoxide. The maximum concentration of dimethyl sulfoxide was $0.1 \%$, which did not affect either the assay for VEGF or western blot analysis.

Cell culture. Cloned osteoblast-like MC3T3-E1 cells, which were derived from newborn mouse calvaria (17), were maintained as previously described (18). Briefly, the cells were cultured in $\alpha$-minimum essential medium ( $\alpha$-MEM) containing $10 \%$ fetal calf serum (FCS) at $37^{\circ} \mathrm{C}$ in a humidified atmosphere of $5 \% \mathrm{CO}_{2} / 95 \%$ air. The cells were seeded into $35-\mathrm{mm}\left(5 \times 10^{4}\right.$ cells/dish) or $90-\mathrm{mm}\left(2 \times 10^{5}\right.$ cells/dish) diameter dishes in $\alpha$-MEM containing $10 \%$ FCS. After 5 days, the medium was replaced with $\alpha$-MEM containing $0.3 \%$ FCS. The cells were used for experiments after $48 \mathrm{~h}$.

Assay for VEGF. The cultured cells were pretreated with various doses of resveratrol, SRT1720 or vehicle for $60 \mathrm{~min}$, and then stimulated with $70 \mathrm{ng} / \mathrm{ml}$ of BMP-4 or vehicle in $1 \mathrm{ml}$ of $\alpha$-MEM containing $0.3 \%$ FCS for the indicated periods. The conditioned medium was collected, and VEGF in the medium was then measured by mouse VEGF ELISA kits according to the manufacturer's protocol.

Real-time RT-PCR. The cultured cells were pretreated with $50 \mu \mathrm{M}$ of resveratrol, $10 \mu \mathrm{M}$ of SRT1720 or vehicle for $60 \mathrm{~min}$, and then stimulated with $70 \mathrm{ng} / \mathrm{ml}$ of BMP-4 or vehicle in $\alpha$-MEM containing $0.3 \%$ FCS for $24 \mathrm{~h}$. Total RNA was isolated and transcribed into complementary DNA using TRIzol reagent and the Omniscript Reverse Transcriptase kit, respectively. Real-time RT-PCR was performed using a LightCycler system in capillaries and FastStart DNA Master SYBR-Green I provided with the kit. Sense and antisense primers for mouse VEGF or GAPDH mRNA were purchased from Takara Bio, Inc. (Tokyo, Japan) (primer set ID: MA039013). The amplified products were determined by melting curve analysis and agarose electrophoresis. VEGF mRNA levels were normalized with those of GAPDH mRNA.

Western blot analysis. The cultured cells were stimulated with BMP-4 for the indicated periods. When indicated, the cells were pretreated with resveratrol or SRT1720 for $60 \mathrm{~min}$. The cells were washed twice with phosphate-buffered saline and then lysed, homogenized and sonicated in a lysis buffer containing $62.5 \mathrm{mM}$ Tris/ $\mathrm{HCl}, \mathrm{pH} 6.8,2 \%$ sodium dodecyl sulfate (SDS), $50 \mathrm{mM}$ dithiothreitol and $10 \%$ glycerol. SDS-polyacrylamide gel electrophoresis (PAGE) was performed by the method described by Laemmli (19) on $10 \%$ polyacrylamide gels. Western blot analysis was performed as described previously (20) by using phospho-specific Smad1/5/8 antibodies, phospho-specific p70 S6 kinase antibodies, p70 S6 kinase antibodies or GAPDH antibodies, with peroxidaselabeled antibodies raised in goat against rabbit IgG being used as secondary antibodies. The peroxidase activity on the PVDF membrane was visualized on X-ray film by means of the ECL western blotting detection system.

Statistical analysis. The data were analyzed by ANOVA followed by Bonferroni method for multiple comparisons between pairs, and values of $\mathrm{P}<0.05$ were considered to indicate statistically significant results. All data are presented as the mean \pm standard error of the mean (SEM) of triplicate determinations from three independent cell preparations.

\section{Results}

Effect of resveratrol on BMP-4-stimulated VEGF release in MC3T3-E1 cells. We previously demonstrated that BMP-4 stimulates the synthesis of VEGF in osteoblast-like MC3T3-E1 cells (8). We first examined the effect of resveratrol on BMP-4-stimulated VEGF release. Resveratrol, which alone had little effect on VEGF levels, significantly suppressed BMP-4-stimulated VEGF release in MC3T3-E1 cells (Fig. 1). The inhibitory effect of resveratrol on VEGF synthesis was dose-dependent in the range between 10 and $70 \mu \mathrm{M}$ (Fig. 2). Resveratrol $(70 \mu \mathrm{M})$ caused an $\sim 70 \%$ decrease in the BMP-4mediated effect.

Effect of resveratrol on BMP-4-induced expression levels of VEGF mRNA in MC3T3-E1 cells. To investigate whether the suppressive effect of resveratrol on BMP-4-stimulated VEGF release is mediated through a transcriptional event, we next examined the effect of resveratrol on BMP-4-induced VEGF mRNA expression. Resveratrol significantly reduced the VEGF mRNA expression levels induced by BMP-4 (Fig. 3).

Effects of SRT1720 on the release of VEGF and the mRNA expression stimulated by BMP-4 in MC3T3-E1 cells. SRT1720 is also known as an activator of SIRT1 as well as resveratrol, and the potencies are estimated to be $\sim 1,000$-fold greater than resveratrol $(21,22)$. Next, we investigated the effect of SRT1720 on BMP-4-stimulated VEGF synthesis in MC3T3-E1 cells. SRT1720, which alone had little effect on 


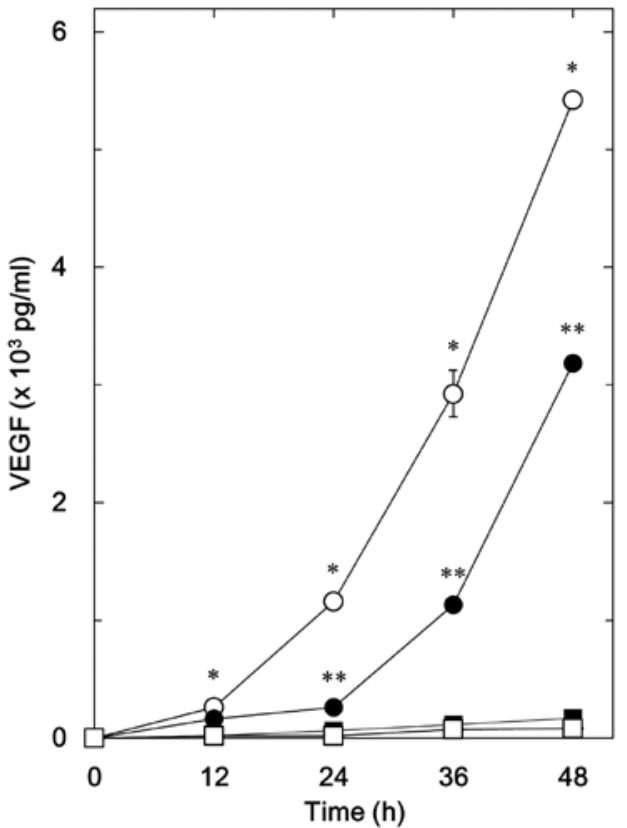

Figure 1. Effect of resveratrol on bone morphogenetic protein-4 (BMP-4) stimulated vascular endothelial growth factor (VEGF) release in MC3T3-E1 cells. The cultured cells were pretreated with $50 \mu \mathrm{M}$ of resveratrol ( $\bullet$ and $\mathbf{\square})$ or vehicle $(O$ and $\square$ ) for $60 \mathrm{~min}$, and then stimulated with $70 \mathrm{ng} / \mathrm{ml}$ of BMP-4 $(\bullet$ and $\bigcirc)$ or vehicle $(\square$ and $\square)$ for the indicated time periods. VEGF concentrations in the culture medium were determined by ELISA. Each value represents the mean \pm standard error of the mean (SEM) of triplicate determinations from three independent cell preparations. "P<0.05, compared to the value of the control; ${ }^{* *} \mathrm{P}<0.05$, compared to the value in cells treated with BMP-4 alone.

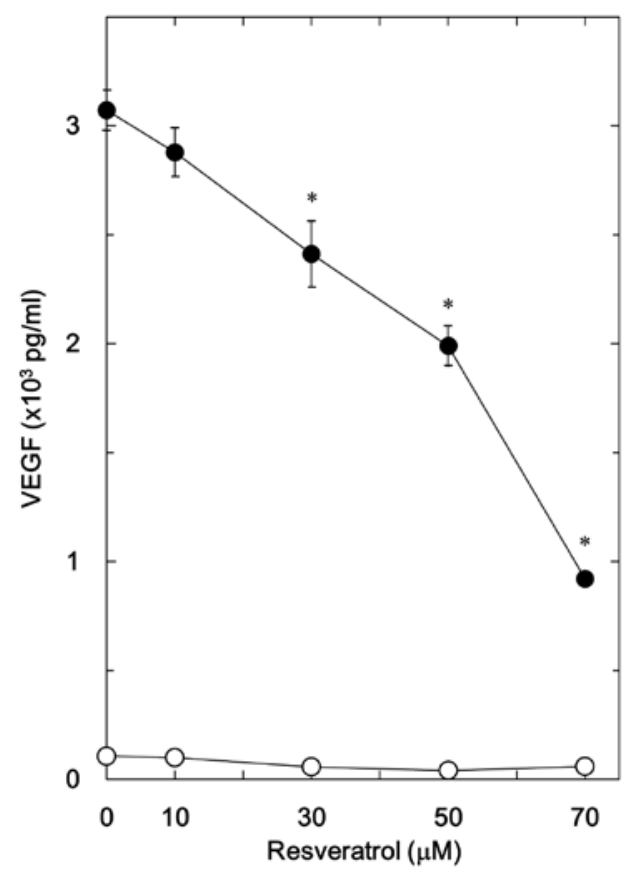

Figure 2. Dose-dependent effect of resveratrol on bone morphogenetic protein-4 (BMP-4)-stimulated vascular endothelial growth factor (VEGF) release in MC3T3-E1 cells. The cultured cells were pretreated with various doses of resveratrol for $60 \mathrm{~min}$, and then stimulated with $70 \mathrm{ng} / \mathrm{ml}$ of BMP-4 (•) or vehicle (O) for $48 \mathrm{~h}$, followed by measurement of VEGF in the respective media. VEGF concentrations in the culture medium were determined by ELISA. Each value represents the mean \pm standard error of the mean (SEM) of triplicate determinations from three independent cell preparations. ${ }^{*} \mathrm{P}<0.05$, compared to the value of the control.

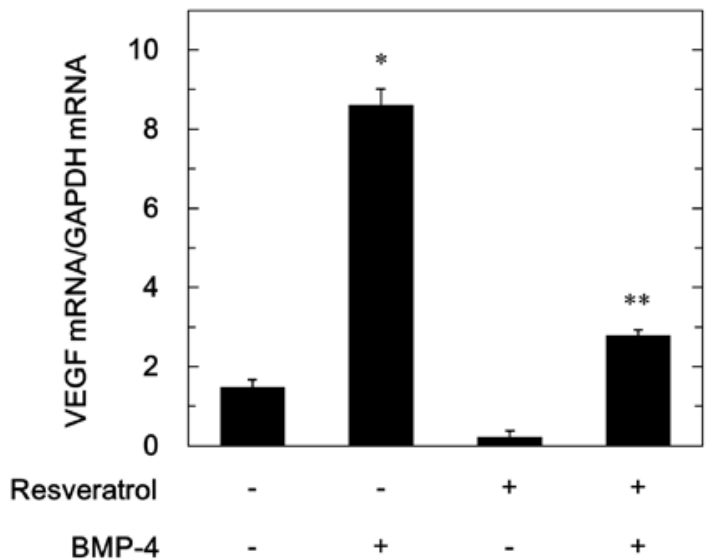

Figure 3. Effect of resveratrol on bone morphogenetic protein-4 (BMP-4)induced expression levels of vascular endothelial growth factor (VEGF) mRNA in MC3T3-E1 cells. The cultured cells were pretreated with $50 \mu \mathrm{M}$ of resveratrol or vehicle for $60 \mathrm{~min}$, and then stimulated with $70 \mathrm{ng} / \mathrm{ml}$ of BMP-4 or vehicle for $24 \mathrm{~h}$. The respective total RNA was then isolated and quantified by real-time RT-PCR. Each value represents the mean \pm standard error of the mean (SEM) of triplicate determinations from three independent cell preparations. ${ }^{*} \mathrm{P}<0.05$ compared to the value of the control; ${ }^{* *} \mathrm{P}<0.05$ compared to the value in cells treated with BMP-4 alone.

Table I. Effect of SRT1720 on BMP-4-stimulated VEGF release in MC3T3-E1 cells.

\begin{tabular}{lcc}
\hline SRT1720 & BMP-4 & VEGF $(\mathrm{pg} / \mathrm{ml})$ \\
\hline- & - & $36.9 \pm 1.2$ \\
- & + & $2577.0 \pm 202.1^{\mathrm{a}}$ \\
+ & - & $32.4 \pm 2.2$ \\
+ & + & $1124.4 \pm 46.1^{\mathrm{b}}$
\end{tabular}

The cultured cells were pretreated with $10 \mu \mathrm{M}$ of SRT1720 or vehicle for $60 \mathrm{~min}$, and then stimulated with $70 \mathrm{ng} / \mathrm{ml}$ of BMP-4 or vehicle for $48 \mathrm{~h}$, followed by measurement of VEGF in the respective media. Each value represents the mean \pm SEM of triplicate determinations from three independent cell preparations. ${ }^{\text {a }}<0.05$, compared to the value of the control. ${ }^{b} \mathrm{P}<0.05$, compared to the value in cells treated with BMP-4 alone. BMP-4, bone morphogenetic protein-4; VEGF, vascular endothelial growth factor.

VEGF release, significantly suppressed the BMP-4-stimulated VEGF release (Table I). In addition, SRT1720, which alone did not affect the VEGF mRNA expression levels, significantly reduced the expression levels of VEGF mRNA induced by BMP-4 (Table II).

Effects of resveratrol or SRT1720 on the BMP-4-induced phosphorylation of Smad1/5/8 in MC3T3-E1 cells. It has been previously established that the effects of BMPs are exerted through the intracellular signaling of Smad proteins such as Smad1, Smad5 and Smad8 (4). In order to clarify whether the inhibitory effect of resveratrol on the BMP-4stimulated VEGF synthesis is mediated by the modification of Smad1/5/8 activation in MC3T3-E1 cells, we examined the effect of resveratrol on the BMP-4-induced phosphorylation of Smad1/5/8. Resveratrol, which alone had little effect on the 
Table II. Effect of SRT1720 on BMP-4-induced expression levels of VEGF mRNA in MC3T3-E1 cells.

\begin{tabular}{lcc}
\hline SRT1720 & BMP-4 & VEGF mRNA/GAPDH mRNA \\
\hline- & - & $1.49 \pm 0.30$ \\
- & + & $8.60 \pm 0.71^{\mathrm{a}}$ \\
+ & - & $1.51 \pm 0.26$ \\
+ & + & $5.94 \pm 0.12^{\mathrm{b}}$ \\
\hline
\end{tabular}

The cultured cells were pretreated with $10 \mu \mathrm{M}$ of SRT1720 or vehicle for $60 \mathrm{~min}$, and then stimulated with $70 \mathrm{ng} / \mathrm{ml}$ of BMP-4 or vehicle for $24 \mathrm{~h}$. The respective total RNA was then isolated and quantified by real-time RT-PCR. Each value represents the mean \pm SEM of triplicate determinations from three independent cell preparations. ${ }^{\text {a }} \mathrm{P}<0.05$ compared to the value of the control. ${ }^{* *} \mathrm{P}<0.05$ compared to the value in cells treated with BMP-4 alone. BMP-4, bone morphogenetic protein-4; VEGF, vascular endothelial growth factor.

A

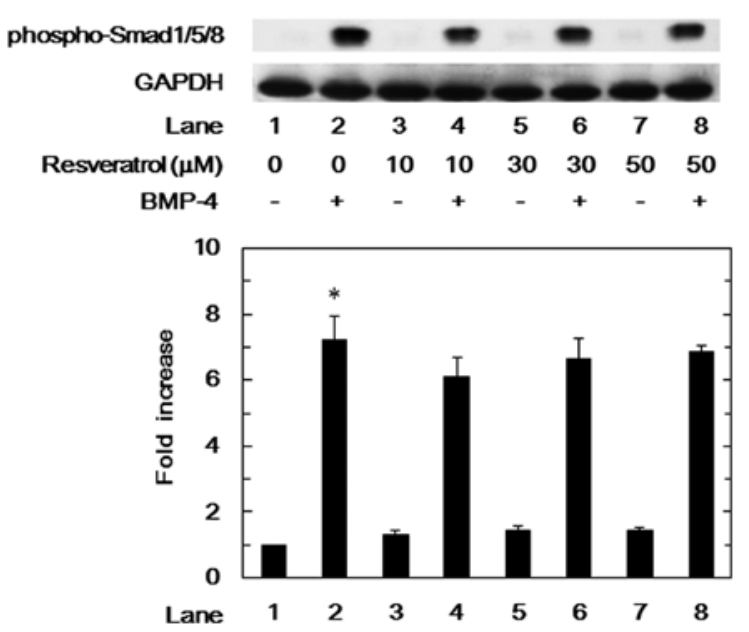

B

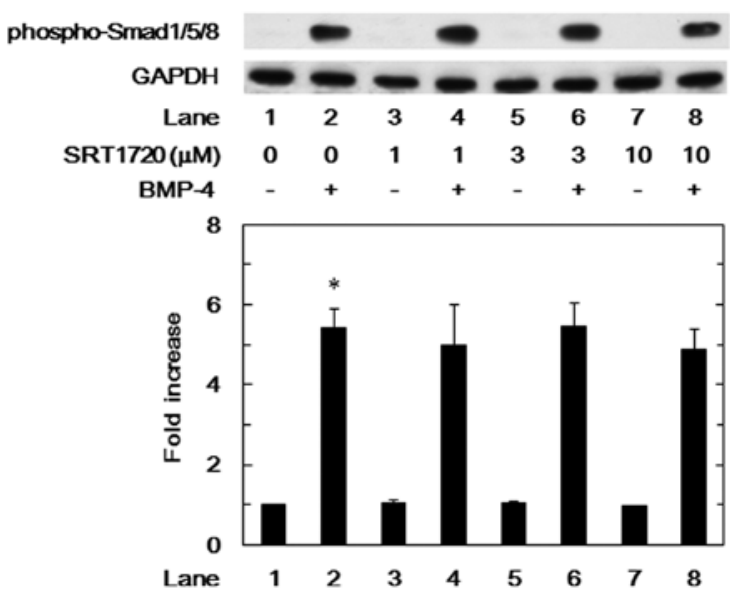

Figure 4. Effect of resveratrol or SRT1720 on bone morphogenetic protein-4 (BMP-4)-induced phosphorylation of Smad1/5/8 in MC3T3-E1 cells. The cultured cells were pretreated with various doses of resveratrol (A) or SRT1720 (B) for $60 \mathrm{~min}$, and then stimulated with $30 \mathrm{ng} / \mathrm{ml}$ of BMP-4 or vehicle for $120 \mathrm{~min}$. The cell extracts were then subjected to sodium dodecyl sulfate-polyacrylamide gel electrophoresis (SDS-PAGE) with subsequent western blot analysis with antibodies against phospho-specific Smad1/5/8 and GAPDH. The histogram shows the quantitative representation of the levels of BMP-4-induced phosphorylation obtained from a laser densitometric analysis of three independent experiments. Each value represents the mean \pm standard error of the mean (SEM) of triplicate determinations. ${ }^{*} \mathrm{P}<0.05$, compared to the value of the control.
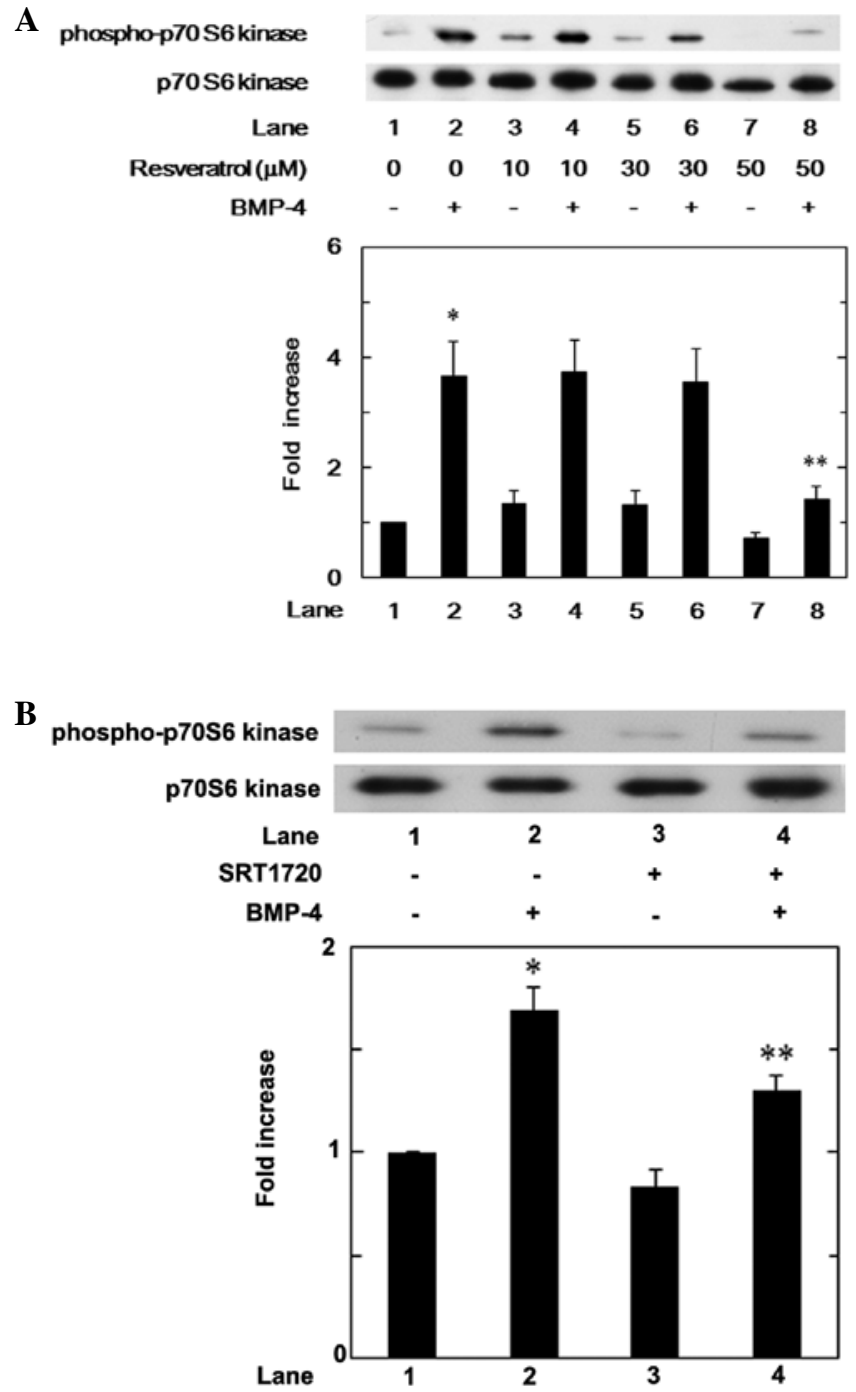

Figure 5. Effect of resveratrol or SRT1720 on bone morphogenetic protein-4 (BMP-4)-induced phosphorylation of p70 S6 kinase in MC3T3-E1 cells. The cultured cells were pretreated with various doses of resveratrol (A) or $10 \mu \mathrm{M}$ of SRT1720 (B) for $60 \mathrm{~min}$, and then stimulated with $30 \mathrm{ng} / \mathrm{ml}$ of BMP-4 or vehicle for $90 \mathrm{~min}$. The cell extracts were then subjected to sodium dodecyl sulfate-polyacrylamide gel electrophoresis (SDS-PAGE) with subsequent western blot analysis with antibodies against phospho-specific p70 S6 kinase and p70 S6 kinase. The histogram shows the quantitative representation of the levels of BMP-4-induced phosphorylation obtained from a laser densitometric analysis of three independent experiments. Each value represents the mean \pm standard error of the mean (SEM) of triplicate determinations. ${ }^{*} \mathrm{P}<0.05$, compared to the value of the control; ${ }^{* *} \mathrm{P}<0.05$, compared to the value in the cells treated with BMP-4 alone.

phosphorylation levels of Smad1/5/8, failed to affect the levels induced by BMP-4 at a dose up to $50 \mu \mathrm{M}$ (Fig. 4A). In addition, SRT1720 did not affect the Smad1/5/8 phosphorylation levels at a dose up to $10 \mu \mathrm{M}$ (Fig. 4B).

Effects of resveratrol or SRT1720 on the BMP-4-induced phosphorylation of p70 S6 kinase in MC3T3-E1 cells. We previously demonstrated that BMP-4 stimulates VEGF synthesis through activation of p70 S6 kinase in osteoblast-like MC3T3-E1 cells (8). In order to elucidate whether the suppressive effect of resveratrol on BMP-4-stimulated VEGF synthesis is mediated by the modulation of p70 S6 kinase activation in 
MC3T3-E1 cells, we examined the effect of resveratrol on the BMP-4-induced phosphorylation of p70 S6 kinase. Resveratrol significantly attenuated the phosphorylation of p70 S6 kinase induced by BMP-4 in a dose-dependent manner between 10 and $50 \mu \mathrm{M}$ (Fig. 5A). Furthermore, SRT1720, which alone barely affected the phosphorylation of p70 S6 kinase, also suppressed the p70 S6 kinase phosphorylation in these cells (Fig. 5B).

\section{Discussion}

In the present study, we demonstrated that resveratrol, a polyphenolic flavonoid enriched in the skins of red grapes or red wine $(12,13)$, significantly suppressed BMP-4-stimulated VEGF release in osteoblast-like MC3T3-E1 cells. Resveratrol reportedly functions at least in part via activation of SIRT1, which is known as one of the longevity genes (21). We also found that SRT1720 suppressed BMP-4-stimulated VEGF release in these cells. Therefore, the suppressive effect of resveratrol on BMP-4-induced VEGF synthesis in osteoblasts appears to be a SIRT1-dependent event. In addition, we demonstrated that both resveratrol and SRT1720 markedly decreased the BMP-4-induced expression levels of VEGF mRNA. Based on our findings, it is probable that the inhibitory effect of resveratrol on BMP-4-induced VEGF release is mediated through transcriptional events. To the best of our knowledge, this is the first report to demonstrate the suppression of VEGF synthesis by resveratrol in osteoblasts.

It is well known that Smad proteins are central mediators of the intracellular signaling system of the TGF- $\beta$ superfamily such as TGF- $\beta$ and BMPs (23). Regarding BMP signaling, BMPs employ the activation of $\mathrm{Smad} 1 / 5 / 8$ as receptor-regulated Smads (23). Thus, we investigated whether Smad1/5/8 are involved in the inhibitory effects of resveratrol or SRT1720 on BMP-4-stimulated VEGF synthesis in osteoblast-like MC3T3-E1 cells. However, neither resveratrol nor SRT1720 affected the BMP-4-induced phosphorylation levels of Smad1/5/8. Therefore, it seems unlikely that the suppressive effect of resveratrol on VEGF synthesis stimulated by BMP-4 is due to the modulation of Smad1/5/8-mediating signaling. Moreover, accumulating evidence indicates that the TGF- $\beta$ superfamily exerts their effects on a variety of biological functions via Smad-independent signaling (24). We previously reported that activation of p70 S6 kinase positively regulates BMP-4-stimulated VEGF synthesis in osteoblastlike MC3T3-E1 cells (8). Thus, we next investigated whether resveratrol or SRT1720 affects the activation of p70 S6 kinase upregulated by BMP-4 in MC3T3-E1 cells. We found that the phosphorylation levels of p70 S6 kinase induced by BMP-4 were significantly attenuated by both resveratrol and SRT1720. Based on our findings, it is likely that the suppression of BMP-4-stimulated VEGF synthesis by resveratrol through SIRT-1 activation is mediated by the modulation of p70 S6 kinase in osteoblast-like MC3T3-E1 cells.

Resveratrol is a natural polyphenol abundantly found in grape skins and red wine and shows numerous favorable effects on the health of humans through antioxidation, anti-aging and anti-stress $(12,13)$. It has been reported that resveratrol prevents various types of cancers such as colon carcinoma, and attenuates the progression of Alzheimer's disease, in addition to protection against obesity and its associated diseases (25-27).
Recent studies have also linked resveratrol to a prolonged lifespan in humans and other species $(28,29)$. It has been shown that BMP signaling is required for both bone development and angiogenesis (30). During bone development and fracture healing, BMPs not only increase bone formation, but also enhance angiogenesis through regulation of the expression of VEGF. Moreover, modifications of VEGF expression were reportedly observed in osteoporosis in vivo (7). Both the reduction in VEGF expression in the tibial metaphysis and the contrasting increases in VEGF expression related to vascularization in the periosteum have been recognized in osteoporotic rat models (7), suggesting the complicated mechanism of the pathogenesis. Thus, our present findings, clearly demonstrating the reduction of BMP-4-induced VEGF synthesis by resveratrol in osteoblasts-like MC3T3-E1 cells, provides novel insight underlying the favorable effects of polyphenols on the health of humans particularly on elder individuals. Further investigation is necessary to clarify the detailed mechanisms of resveratrol underlying the VEGF synthesis in osteoblasts.

In conclusion, our findings strongly suggest that resveratrol attenuates BMP-4-stimulated VEGF synthesis through suppression of the activation of p70 S6 kinase in osteoblasts, and that the inhibitory effect is at least in part mediated by SIRT1 activation.

\section{Acknowledgements}

We are grateful to Yumiko Kurokawa for her skillful technical assistance. This investigation was supported in part by a Grant-in-Aid for Scientific Research (19591042) from the Ministry of Education, Science, Sports and Culture of Japan, the Foundation for Growth Science, and the Research Funding for Longevity Sciences (22-4, 23-9) from the National Center for Geriatrics and Gerontology (NCGG), Japan.

\section{References}

1. Karsenty G and Wagner EF: Reaching a genetic and molecular understanding of skeletal development. Dev Cell 2: 389-406, 2002.

2. Boyce BF and Xing L: Functions of RANKL/RANK/OPG in bone modeling and remodeling. Arch Biochem Biophys 473: 139-146, 2008.

3. Parfitt AM: Targeted and nontargeted bone remodeling: relationship to basic multicellular unit origination and progression. Bone 30: 5-7, 2002.

4. Miyazono K, Maeda S and Imamura T: BMP receptor signaling: transcriptional targets, regulation of signals, and signaling crosstalk. Cytokine Growth Factor Rev 16: 251-263, 2005.

5. Krause C, de Gorter DJJ, Karperien M and ten Dijke P: Signal transduction cascades controlling osteoblast differentiation. In: Primer on the Metabolic Bone Diseases and Disorders of Mineral Metabolism. Rosen CJ (ed). 7th edition. American Society for Bone and Mineral Research, Washington, pp10-16, 2008.

6. Yamaguchi K, Nagai S, Ninomiya-Tsuji J, Nishita M, Tamai K, Irie K, Ueno N, Nishida E, Shibuya H and Matsumoto K: XIAP, a cellular member of the inhibitor of apoptosis protein family, links the receptors to TAB1-TAK1 in the BMP signaling pathway. EMBO J 18: 179-187, 1999.

7. Clarkin CE and Gerstenfeld LC: VEGF and bone cell signalling: an essential vessel for communication? Cell Biochem Funct 31 : 1-11, 2013.

8. Kozawa O, Matsuno $\mathrm{H}$ and Uematsu T: Involvement of p70 S6 kinase in bone morphogenetic protein signaling: vascular endothelial growth factor synthesis by bone morphogenetic protein-4 in osteoblasts. J Cell Biochem 81: 430-436, 2001. 
9. Tokuda H, Hatakeyama D, Shibata T, Akamatsu S, Oiso Y and Kozawa O: p38 MAP kinase regulates BMP-4-stimulated VEGF synthesis via p70 S6 kinase in osteoblasts. Am J Physiol Endcrinol Metab 284: E1202-E1209, 2003.

10. Jankun J, Selman SH, Swiercz R and Skrzypczak-Jankun E: Why drinking green tea could prevent cancer. Nature 387: 561, 1997.

11. Harborne JB and Williams CA: Advances in flavonoid research since 1992. Phytochemistry 55: 481-504, 2000.

12. Blander G and Guarente L: The Sir2 family of protein deacetylases. Annu Rev Biochem 73: 417-435, 2004.

13. Koo SH and Montminy M: In vino veritas: a tale of two sirt1s? Cell 127: 1091-1093, 2006.

14. Baur JA, Pearson KJ, Price NL, Jamieson HA, Lerin C, Kalra A Prabhu VV, Allard JS, Lopez-Lluch G, Lewis K, Pistell PJ, Poosala S, Becker KG, Boss O, Gwinn D, Wang M, Ramaswamy S, Fishbein KW, Spencer RG, Lakatta EG, Le Couteur D, Shaw RJ, Navas P, Puigserver P, Ingram DK, de Cabo R and Sinclair DA: Resveratrol improves health and survival of mice on a highcalorie diet. Nature 444: 337-342, 2006.

15. Mizutani K, Ikeda K, Kawai Y and Yamori Y: Resveratrol stimulates the proliferation and differentiation of osteoblastic MC3T3-E1 cells. Biochem Biophys Res Commun 253: 859-863, 1998.

16. Kupisiewicz K, Boissy P, Abdallah BM, Hansen FD, Erben RG, Savouret JF, Søe K, Andersen TL, Plesner T and Delaisse JM: Potential of resveratrol analogues as antagonists of osteoclasts and promoters of osteoblasts. Calcif Tissue Int 87: 437-449, 2010.

17. Sudo H, Kodama HA, Amagai Y, Yamamoto S and Kasai S: In vitro differentiation and calcification in a new clonal osteogenic cell line derived from newborn mouse calvaria. J Cell Biol 96: 191-198, 1983

18. Kozawa O, Tokuda H, Miwa M, Kotoyori J and Oiso Y: Cross-talk regulation between cyclic AMP production and phosphoinositide hydrolysis induced by prostaglandin $\mathrm{E}_{2}$ in osteoblast-like cells. Exp Cell Res 198: 130-134, 1992.

19. Laemmli UK: Cleavage of structural proteins during the assembly of the head of bacteriophage T4. Nature 227: 680-685, 1970.

20. Kato K, Ito H, Hasegawa $\mathrm{K}$, Inaguma $\mathrm{Y}$, Kozawa $\mathrm{O}$ and Asano $\mathrm{T}$ Modulation of the stress-induced synthesis of hsp27 and $\alpha \mathrm{B}$-crystallin by cyclic AMP in C6 rat glioma cells. J Neurochem 66: 946-950, 1996.
21. Bradamante $S$, Barenghi L and Villa A: Cardiovascular protective effects of resveratrol. Cardiovasc Drug Rev 22: 169-188, 2004.

22. Milne JC, Lambert PD, Schenk S, Carney DP, Smith JJ, Gagne DJ, Jin L, Boss O, Perni RB, Vu CB, Bemis JE, Xie R, Disch JS, Ng PY, Nunes JJ, Lynch AV, Yang H, Galonek H, Israelian K, Choy W, Iffland A, Lavu S, Medvedik O, Sinclair DA, Olefsky JM, Jirousek MR, Elliott PJ and Westphal CH: Small molecule activators of SIRT1 as therapeutics for the treatment of type 2 diabetes. Nature 450: 712-716, 2007.

23. Miyazawa K, Shinozaki M, Hara T, Furuya T and Miyazono K: Two major Smad pathways in TGF- $\beta$ superfamily signalling. Genes Cells 7: 1191-1204, 2002.

24. Moustakas A and Heldin CH: Non-Smad TGF-beta signals. J Cell Sci 118: 3573-3584, 2005.

25. Kundu JK and Surh YJ: Cancer chemopreventive and therapeutic potential of resveratrol: mechanistic perspectives. Cancer Lett 269: 243-261, 2008.

26. Ramassamy C: Emerging role of polyphenolic compounds in the treatment of neurodegenerative diseases: a review of their intracellular targets. Eur J Pharmacol 545: 51-64, 2006.

27. Li F, Gong Q, Dong H and Shi J: Resveratrol, a neuroprotective supplement for Alzheimer's disease. Curr Pharm Des 18: 27-33, 2012.

28. Howitz KT, Bitterman KJ, Cohen HY, Lamming DW, Lavu S, Wood JG, Zipkin RE, Chung P, Kisielewski A, Zhang LL, Scherer B and Sinclair DA: Small molecule activators of sirtuins extend Saccharomyces cerevisiae lifespan. Nature 425: 191-196, 2003.

29. Wood JG, Rogina B, Lavu S, Howitz K, Helfand SL, Tatar M and Sinclair D: Sirtuin activators mimic caloric restriction and delay ageing in metazoans. Nature 430: 686-689, 2004.

30. Zhang F, Qiu T, Wu X, Wan C, Shi W, Wang Y, Chen JG, Wan M, Clemens TL and Cao X: Sustained BMP signaling in osteoblasts stimulates bone formation by promoting angiogenesis and osteoblast differentiation. J Bone Miner Res 24: 1224-1233, 2009. 